\title{
Representação social acerca dos animais e bioética de proteção: subsídios à construção da educação humanitária
}

Joseth Filomena de Jesus Souza ${ }^{1}$, Helena Eri Shimizu ${ }^{2}$

\section{Resumo}

O presente estudo visa identificar as representações sociais que crianças do ensino fundamental de uma escola pública de Brasília/DF fazem sobre os animais. Quatro grupos focais foram realizados e os dados, interpretados a partir da bioética de proteção, que defende que pacientes morais suscetíveis ou vulnerados a danos devem ser protegidos. $O$ estudo considera ser relevante conhecer as representações sociais de estudantes sobre os animais, com vistas a subsidiar medidas educativas eficazes que contribuam para evitar que se continue a atribuir valor instrumental aos animais. Os dados mostram que a representação dos participantes fundamenta-se no afeto e na empatia por cães e gatos, e no especismo eletivo referente a algumas espécies. A partir dos resultados, foi possível constatar que as crianças tendem a seguir a forma socialmente conotada de classificação, indicando a necessidade de adotar medidas educativas para futuramente romper o padrão antropocêntrico que pauta as relações humanas com as outras espécies.

Palavras-chave: Animais. Bioética. Educação. Teoria das representações sociais.

\section{Resumen}

La representación social acerca de los animales y la bioética de protección: subsidios a la construcción de la educación humanitaria

El presente estudio tiene como objetivo identificar las representaciones sociales que los niños de primaria de una escuela pública de Brasilia, Distrito Federal hacen sobre los animales. Se llevaron a cabo cuatro grupos de discusión, y los datos, interpretados a partir de la bioética de protección, que defiende que los pacientes morales susceptibles o vulnerables a daños deban ser protegidos. El estudio considera que es relevante conocer las representaciones sociales de los estudiantes acerca de los animales, para apoyar subsidios educativos eficaces que contribuyan evitar que se continúe a atribuir valor instrumental a los animales. Los datos muestran que la representación de los participantes se basa en el afecto y la empatía hacia los perros y gatos, y en el especismo electivo, referente a algunas especies. A partir de los resultados, fue posible constatar que los niños tienden a seguir la forma socialmente connotada de clasificación, indicando la necesidad de adoptar medidas educativas para que un futuro se rompa con el patrón antropocéntrico que pauta las relaciones humanas con otras especies.

Palabras-clave: Animales. Bioética. Educación. Teoría de la representación social.

\section{Abstract}

The social representation of animals and bioethics of protection: subsidies to build up humanitarian education

This study aims to identify the social representations that elementary school children from a public school in Brasilia, Federal District do about animals. Four focus groups were conducted with elementary school children, and the data were interpreted in the light of bioethics of protection, which argues that moral patients that are either harmed or vulnerable to damage must be protected. The study considers that it is relevant to know the social representations of students about the animals to support effective educational measures, which will help prevent the continued instrumental value assigned to animals. The data show that this representation is based on affection and empathy for dogs and cats, and elective speciesism, related to some species. The finding is that children tend to follow a socially connoted classification, indicating the need to adopt educational measures to further break the anthropocentric pattern that guides human relationships with other species. Key words: Animals. Bioethics. Education. Social representation theory.

\section{Aprovação CEP/FS-UnB - 165/10}

1. Mestra souzajoseth@yahoo.com.br 2. Doutora shimizu@unb.br - Universidade de Brasília (UnB), Brasília/DF, Brasil.

\section{Correspondência}

Helena Eri Shimizu - SQN 205, bloco G, apt 605 CEP 70843-070. Brasília/DF, Brasil.

Declaram não haver conflito de interesse. 
Data dos anos 1970 a maior preocupação quanto à necessidade de proteger os animais e, também, a intensificação do debate sobre a moralidade da utilização que deles se faz. $O$ que pode ser explicado por diversos fatores, tais como a crise ambiental que tem suscitado debates sobre questões relacionadas ao domínio do homem sobre a natureza; o avanço do conhecimento científico sobre as capacidades e emoções dos animais; a publicação de importantes obras denunciando e questionando a legitimidade da exploração animal, bem como o surgimento da bioética ${ }^{1}$.

Desde então, o movimento em prol dos animais está em constante crescimento e cada vez mais tem pressionado a criação de leis e regulamentações protetivas ${ }^{1}$. No Brasil, por exemplo, aprovou-se a Lei $11.794 / 08$ que regulamenta o uso de animais no ensino e nas pesquisas científicas ${ }^{2}$. Entretanto, ainda hoje os animais são considerados pelo que podem oferecer ou render aos humanos ${ }^{3}$, tornando evidente o predomínio da ética tradicional antropocêntrica na qual os animais não humanos são subjugados e possuem valor instrumental. Desse modo, a exploração de animais na sociedade, além de muito frequente, é naturalizada e pouco questionada. Para citar alguns exemplos, têm-se animais para entretenimento (zoológicos, rodeios, vaquejadas, circos etc.), alimentação, experimentos científicos, extração de pele e labor (transporte e tração) ${ }^{3}$.

A exploração de indivíduos com defesas frágeis é moralmente inadequada é inaceitável, vez que desconsidera os danos possíveis a serem causados. Além disso, os animais não humanos são seres sencientes que possuem interesses próprios, mas não conseguem se defender ante interesses especistas. A coisificação dos animais e a consequente exploração a que são submetidos é um problema com sérias implicações morais e deve ser analisado à luz da bioética ${ }^{4}$.

Nesse sentido, cabe ressaltar a pertinência da bioética de proteção como ferramenta teórica para a análise deste tema, dado referir-se à ética aplicada às condutas humanas que podem ocasionar consequências irreversíveis sobre seres indefesos, sendo necessário, assim, proteger aqueles que estão suscetíveis a danos ou vulnerados ${ }^{5}$.

Como tutor dos animais, o Estado deve implementar políticas visando mudanças na relação do homem com os animais. Para tal objetivo, a educação é imprescindível, sobretudo às crianças, futuros tomadores de decisão. Uma intervenção pedagógica eficaz requer o conhecimento das concepções que as crianças em idade escolar estão construindo ante este novo contexto que se delineia na sociedade acerca dos animais e dos conteúdos sobre eles abordados na escola. Sob tal contexto, este estudo utilizou a teoria das representações sociais (TRS). Ressalte-se que as representações sociais (RS) são uma forma de conhecimento elaborada por determinado grupo sobre um objeto social, assumindo importância ao exercer funções como as de guiar comportamentos e facilitar a comunicação entre os membros do grupo que as compartilha ${ }^{6}$.

Por este motivo, o presente trabalho objetiva identificar e compreender qual a representação social de crianças acerca dos animais diante dos novos e velhos contextos, analisando-a à luz da bioética, bem como refletir sobre as possíveis intervenções pedagógicas com vistas a contribuir para novos olhares e condutas na relação humana com estes seres.

\section{A bioética de proteção}

A bioética de proteção é uma recente vertente teórica no campo da bioética. Inicialmente, foi formulada pelos pesquisadores latino-americanos Schramm e Kottow para responder conflitos e dilemas morais enfrentados na saúde pública dos países em desenvolvimento, que muitas vezes não conseguem ser resolvidos pelas ferramentas bioéticas tradicionais, em particular o principialismo ${ }^{7}$. A seguir, foi estendida às práticas que ocorrem com outros seres vivos e o ambiente natural e posteriormente modificada pelas ações humanas na idade da vigência da biotecnociência, da biopolítica e da globalização ${ }^{8}$.

A bioética de proteção pode ser definida como uma ética aplicada referente às práticas humanas que podem ter efeitos significativos e irreversíveis sobre outros seres vivos ${ }^{7}$. Assim, esta perspectiva bioética se refere à proteção de pacientes morais que não têm os meios para, sozinhos, se defender das práticas de agentes morais ${ }^{5}$. Para enfrentar os conflitos de interesses e de valores que emergem de tais práticas, a bioética de proteção possui tripla função: além de descritiva e normativa, apresenta uma função protetora ${ }^{9}$.

Esta ferramenta, como indica a própria palavra, visa proteger ou dar amparo, em tais conflitos, à vida dos envolvidos, humanos ou não, para que tenham possibilidades de continuar "sendo" 7. Lato sensu, a bioética de proteção amplia o escopo da consideração moral e se aplica aos animais sencientes, porque os atos humanos podem acarretar-lhes danos ${ }^{7}$. Esta aplicação se justifica, pois existem interesses não especistas, coletivos e ecológicos que 
não podem ser subsumidos a interesses individuais, de corporações, nações, regiões e espécies ${ }^{5}$.

Faz-se importante destacar três tipos de vulnerabilidade: a vulnerabilidade primária, a suscetibilidade e a vulneração. A vulnerabilidade primária é condição ontológica de todo ser vivo e, consequentemente, universal, que não pode ser protegida pois inerente à vida, dado que todo ser vivente irá perecer, independentemente das condições de sua existência. A suscetibilidade indica que o ser vulnerável por natureza está efetivamente ameaçado, encontrando-se em situação que afeta negativamente sua existência. A suscetibilidade pode ou não tornar-se vulneração, que se refere ao estado em que o ser é concretamente afetado por condições adversas, que independem de seu controle ${ }^{5}$.

Desse modo, mediante a exploração dos animais por interesses humanos, estes seres são pacientes morais suscetíveis (ameaçados) - na maior parte das vezes já vulnerados (afetados) - e que precisam de ações urgentes de proteção. Nas palavras de Assumpção (...) esses animais não humanos, criados para determinados fins humanos, são pacientes morais em situação de vulneração, logo, são merecedores de proteção. Não reconhecê-los como tais e, consequentemente, não agir para por fim a essa situação, seria como assumir uma atitude condescendente para com a tirania e contrária ao esforço da ética. Pois o não atuar contra, de fato, é um agir a favor, é uma legitimação da moral antropocêntrica vigente ${ }^{10}$.

De acordo com o Decreto 24.645/34, todos os animais do país são tutelados do Estado ${ }^{11}$. O Brasil se destaca como um dos poucos países a tratar a crueldade para com os animais em nível constitucional. Além da Constituição, a Lei 9.605/98 ${ }^{12}$ é outro importante instrumento de coerção às práticas de violências contra os animais ${ }^{3}$. O país também é signatário da Declaração Universal dos Direitos dos Animais, proclamada pela Organização das Nações Unidas para a Educação, a Ciência e a Cultura ${ }^{13}$. 0 corpus desta declaração deixa clara a situação de suscetibilidade e vulneração em que os animais se encontram, e ante tal fato elenca uma série de dispositivos para protegê-los.

Esta compreensão está em consonância com a Declaração Universal sobre Bioética e Direitos Humanos ${ }^{14}$, que embora eivada de antropocentrismo ético inclui dentre suas preocupações os problemas morais referentes ao meio ambiente e, em particular, aos animais. Porém, conforme Levai ${ }^{3}$, para a real proteção aos animais não bastam leis; é necessária rigorosa estratégia pedagógica rumo a uma cultura de paz. Com base na perspectiva da bioética de pro- teção e nos compromissos assumidos pelo Estado no que concerne aos animais, defende-se neste trabalho sua responsabilidade em promover e fomentar na educação novos olhares sobre os animais.

\section{Teoria das representações sociais}

A TRS foi desenvolvida a partir da obra La psychanalyse, son image et son public, de Serge Moscovici, lançada em 1961. Esta publicação teve como objeto de estudo a psicanálise e o fenômeno da absorção desta ciência pelo senso comum, mediante a comunicação e a linguagem, construindo outro tipo de conhecimento ${ }^{15}$. As RS podem ser definidas como (...) forma de conhecimento, socialmente elaborada e partilhada, com um objetivo prático, e que contribui para a construção de uma realidade comum a um conjunto social ${ }^{16}$.

As RS são construídas a partir de informações recebidas de diferentes fontes sobre o objeto, tais como mídia, diálogo entre pares, leis, ciências e o próprio contato com o objeto ${ }^{17}$. Em decorrência, as crianças nascem em um mundo já estruturado pelas RS de sua comunidade ${ }^{18}$. Para fazer parte do grupo social a que pertencem esses atores sociais, na interação com os indivíduos e com as instituições, captam as informações e as elaboram. A partir daí contribuem com suas próprias RS para a edificação da sociedade ${ }^{19}$.

São dois os processos pelos quais as representações são construídas: a objetivação e a ancoragem. A objetivação torna material aquilo que é abstrato, transformando um conceito em imagem concreta e significativa de algo. Neste processo há uma construção seletiva e uma simplificação das informações acerca do objeto, sendo algumas delas mais consideradas que outras ${ }^{6}$.

A ancoragem consiste em, mediante alguns ajustes, assimilar os novos elementos de um objeto em um sistema de categorias familiares já existentes. Ao ancorar o indivíduo, integra o objeto da representação em um quadro assimilável e compreensível para si mesmo, de acordo com seu sistema de valores, denominando e classificando-o de acordo com a ligação do objeto com sua inserção social ${ }^{6}$.

Ressalta-se o caráter dinâmico das RS, pois estão sujeitas a mudanças, devido ao surgimento de novas representações ou pela reelaboração das existentes. Desse modo, verifica-se transformações nas representações quer por um novo fato ou informação, quer por pontos de conflito, falta de sentido ou algo não familiar nas estruturas representacionais de cada cultura ${ }^{18}$. Distinguem-se quatro funções das representações sociais: 
- Função de saber: as representações sociais permitem que os atores sociais adquiram novos conhecimentos e os integrem a saberes anteriores. Além disso, são condição necessária para a comunicação social, permitindo as trocas sociais, a transmissão e a difusão do conhecimento não científico;

- Função identitária: as representações sociais situam os indivíduos e os grupos no campo social, permitindo-Ihes a elaboração de uma identidade social e pessoal gratificante, compatível com o sistema de normas e valores determinados histórica e socialmente;

- Função de orientação: as representações guiam os comportamentos e as práticas de três formas: intervêm diretamente na definição da finalidade da situação, produzem um sistema de antecipações e expectativas e são prescritivas de comportamentos ou práticas obrigatórias, definindo o que é lícito, tolerável ou inaceitável em um dado contexto social;

- Função justificadora: as representações sociais permitem, a posteriori, justificar as tomadas de posição e dos comportamentos, e também preservar e justificar a diferenciação social, contribuindo para manter a distância social entre grupos ${ }^{20}$.

Tal como mencionado, desde a década de 70 as discussões sobre a forma como os animais são tratados pelos seres humanos se intensificaram no meio acadêmico e têm alcançado significativa amplitude nos meios de comunicação na contemporaneidade ${ }^{21}$. Por conseguinte, torna-se cada vez mais relevante investigar as representações sociais sobre os animais.

\section{Método}

A pesquisa foi realizada na Escola Classe 206 Sul de Brasília/DF. Esta escola foi escolhida por desenvolver um projeto com um dos eixos estruturantes: a Educação Humanitária - voltada a mudanças na relação entre os seres humanos e os animais.

Trinta e dois estudantes participaram da pesquisa, 16 meninas e 16 meninos, cujos critérios de inclusão foram: pertencer a turmas provenientes do $1^{\circ}$ ao $5^{\circ}$ ano do ensino fundamental e estar na faixa entre 7 e 11 anos de idade. Desta forma, buscou-se garantir que tivessem capacidade de compreender o objeto de pesquisa, bem como saber se expressar diante das atividades propostas. Foi realizado um sorteio, de modo a contemplar estudantes de todas as turmas da escola, e houve assinatura de termo de consentimen- to livre e esclarecido (TCLE) pelo responsável e posterior assentimento pelo indivíduo sujeito da pesquisa.

Para a coleta de dados foram utilizados grupos focais com o fim de se observar a reação dos sujeitos ante as falas do outro e as divergências e o consenso emergente acerca de um tema. O grupo focal se torna uma "entidade em si mesma" e desenvolve uma identidade compartilhada, um "nós" que acaba por gerar um ambiente mais próximo do cotidiano, no qual os sujeitos consideram as opiniões dos outros na formulação de suas respostas ${ }^{22}$.

Foram compostos quatro grupos focais durante o mês de julho de 2011, conduzidos por um moderador e um observador. Cada grupo abrangia oito estudantes e o encontro teve a duração aproximada de 35 minutos. Por se tratar de crianças, optou-se por um procedimento lúdico, no qual os quatro grupos focais deveriam construir uma história, de forma coletiva, a partir do trecho seguinte: Em um dia de sol, Eduardo/ Cecilia saíram para passear. Quando estavam caminhando viram um animal... A partir deste trecho as crianças eram incitadas a responder algumas questões de forma a manifestar o que pensam sobre os animais e a relação com eles estabelecida.

Os grupos focais tiveram o áudio literalmente transcrito e colocado em formato necessário para ser analisado pelo software Alceste (Analyse Lexicale par Contexte d'un Ensemble de Segments de Texte), para análise léxica e semântica do texto, mediante a síntese e organização das informações mais importantes. O programa permite identificar as recorrências e os contextos desiguais, considerando agrupamentos linguísticos semelhantes e repetitivos. O momento seguinte comporta a realização da classificação hierárquica descendente que forma eixos e classes de palavras em função da frequência, da associação entre as palavras e destas com suas respectivas classes (cálculo do qui-quadrado) - processo que possibilita a reconstituição do "discurso coletivo" ${ }^{23}$.

Os estudantes participaram voluntariamente da pesquisa com a devida autorização dos pais e assinatura do TCLE. O projeto foi analisado e aprovado pelo Comitê de Ética em Pesquisa da Faculdade de Ciências da Saúde da Universidade de Brasília (UnB).

\section{Resultados}

Da análise do corpus dos quatro grupos focais, realizada pelo Alceste, emergiram três classes divididas em dois eixos temáticos, conforme demonstra o dendograma (Figura 1). 
Figura 1. Dendograma com a estrutura do corpus total obtido das narrativas das crianças ( $\mathrm{N}=32)$

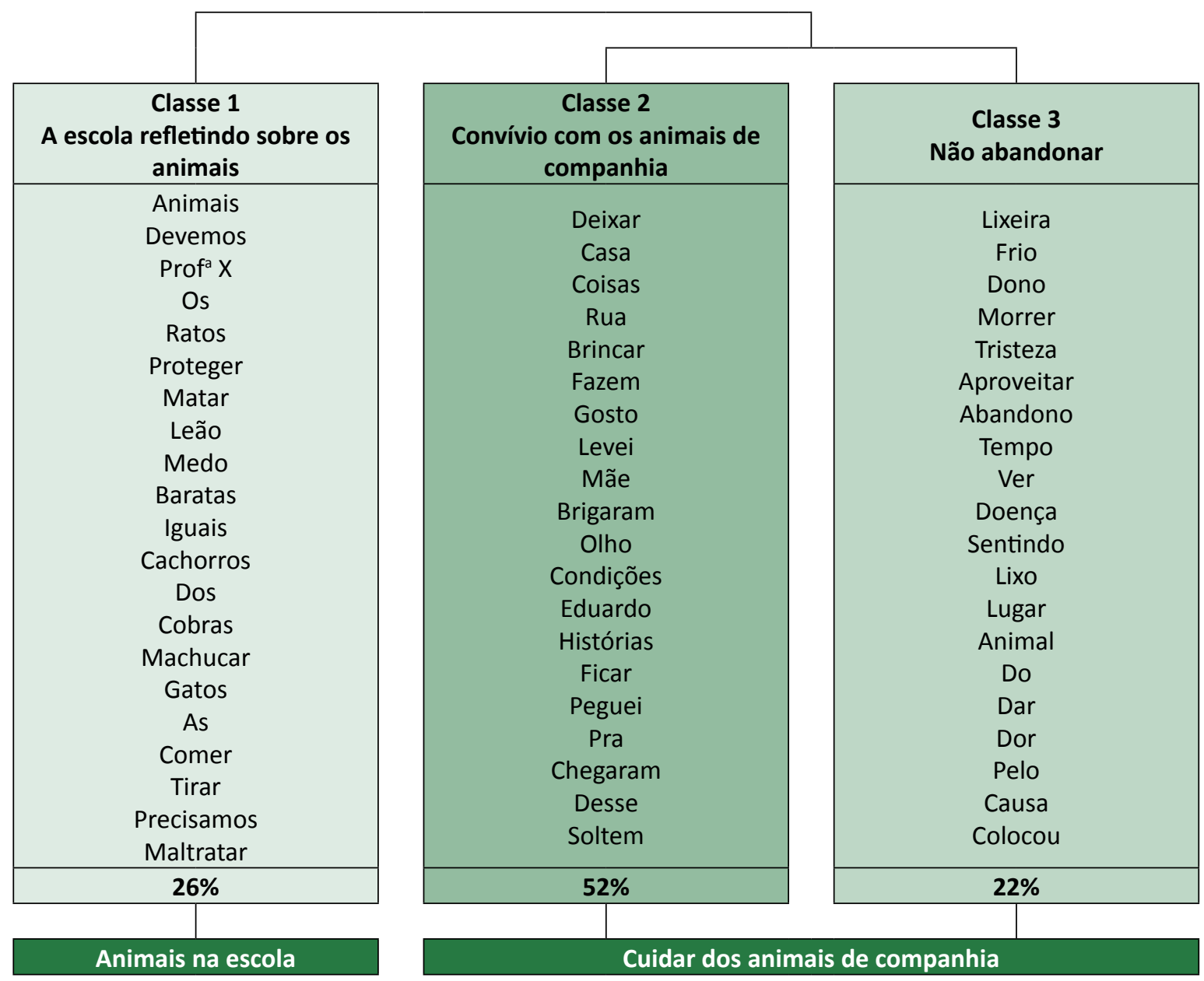

\section{Eixo 1 - Os animais na escola}

- Classe 1-A escola refletindo sobre os animais

Este eixo é composto pela Classe 1 e corresponde a $26 \%$ do corpus analisado. Trata do que é discutido sobre os animais na sala de aula e os posicionamentos dos alunos em relação a alguns deles. Assim, pode se atribuir o seguinte discurso aos sujeitos: " $A$ professora $X$ disse que nós não devemos machucar $e$ nem maltratar os animais, pois eles são iguais à gente. Também disse que precisamos tirar os cachorros e gatos da rua, pois eles não sabem arrumar o que comer. Além disso, ela ensinou que não devemos matar os animais e sim protegê-los. Mas, nós achamos que o leão é feroz e não precisa ser protegido. $E$ as cobras, os ratos e as baratas também não. Eles dão medo e a gente mata". Esta fala reúne o discurso das crianças sobre os conteúdos abordados nas aulas e sua compreensão sobre a forma como os animais devem ser tratados pelo ser humano.
As lições mais lembradas pelos estudantes referem-se à manutenção da integridade física e emocional dos animais, tais como não maltratar, não matar, proteger e cuidar dos animais de forma generalizada. Animais como cães e gatos foram lembrados em função da dependência de cuidados humanos para viver. Além destes, os animais silvestres foram destacados nesta classe dentre os assuntos debatidos na escola, referidos como desprovidos de proteção mediante a exploração de que são vítimas, como o tráfico e a caça. Também houve a recomendação de não adquiri-los como animais de estimação. A ênfase do discurso se concentra nas consequências dessas práticas para os animais:

"Que nós não devemos maltratar os animais, que devemos cuidar e ter amor e união com eles"; "É que a gente não pode levar nenhum animal silvestre pra dentro de casa porque se a gente levar não teremos 
condições de manejar eles. Tipo, se a gente trouxer uma arara pra morar junto com a gente ela vai querer voar um dia, e como os vidros são transparentes ela pode bater com a cara no vidro e quebrar o bico"; "É como lá na nossa sala fala que silvestre não é pet. A professora X tem até uma camiseta".

Observaram-se, também, muitas referências acerca da senciência e dos direitos dos animais. Os direitos trabalhados com estas crianças são definidos na Declaração Universal dos Direitos dos Animais ${ }^{13}$, sendo os mais citados aqueles relacionados com os seguintes artigos: Art. $2^{\circ}$ a) Todo animal tem o direito a ser respeitado; b) O homem, como espécie animal, não pode exterminar os outros animais ou explorá-los violando esse direito; tem o dever de pôr os seus conhecimentos ao serviço dos animais; c) Todo animal tem o direito à atenção, aos cuidados e à proteção do homem; Art. $3^{\circ}$ Nenhum animal será submetido nem a maus tratos nem a atos cruéis (...).

As crianças também fazem menção à igualdade entre humanos e animais não humanos negando a superioridade humana sobre os demais, ao realizarem as seguintes afirmações: "Que a vida deles vale a mesma coisa que a nossa"; "Tomar cuidado com eles porque eles também têm sentimentos"; "Não maltratar. A professora $X$ me emprestou um filme em que os animais é... igual a gente"; "Que nós também somos animais, só que somos animais racionais e eles são animais irracionais"; "Eles são do mesmo jeito, iguais à gente, só não pensam igual à gente".

Nesta classe o grupo destaca a importância de se proteger os animais de estimação (cão, gato, coelho, passarinhos), os animais em extinção e os silvestres que mais despertam simpatia (p.ex., elefante e girafa). As razões citadas para esta proteção foram: "Sofrem muito", "São fofos", "Podem sumir pra sempre", "Não conseguem cuidar de si mesmos". Dentre os animais que não merecem proteção, os mais citados foram baratas, aranhas, escorpiões, ratos e cobras, com a justificativa de que são "nojentos", "perigosos" e "asquerosos".

Quando a pesquisadora insere o rato no lugar do animal por eles escolhidos na construção da história, as falas passam a ter a seguinte conotação: "Ele ia querer, ou assustar o rato pra ele ir embora, ou senão ia querer matar o rato praticamente"; "Porque muita gente tem nojo de rato e não gosta deles"; "Ele mataria"; "Pegar é que não ia"; "Ele envenenaria"; "Ah, ou talvez alguma pessoa ia fazer alguma coisa com o rato"; "Uma experiência. É, experiência nele"; "Mesmo assim, ele ia matar ele. Ele podia passar doença".
Eixo 2 - Cuidar dos animais de companhia

- Classe 2 - Vivência com os animais de companhia

Esta classe explica $52 \%$ do corpus analisado e nela surge um discurso organizado em torno da experiência cotidiana deste grupo social com os animais de companhia. Destacam-se o afeto, os benefícios advindos da relação com o animal, bem como seus "pontos negativos", referindo-se especialmente à bagunça que eventualmente fazem. Todos esses aspectos da convivência com os animais despertam empatia, cuidado e vínculo afetivo.

Com base nos termos que atribuem maior significado a esta classe, pode-se construir o discurso coletivo, isto é, aquele mais amplamente partilhado pelo grupo, sem se referir especificamente a nenhum sujeito: "Eu gosto muito de cachorros e de brincar com eles. Por isso, quando eu vi na rua um cachorro abandonado com uma pinta no olho que nem eu, peguei e levei pra casa pra cuidar. Quando os meus pais chegaram, brigaram comigo e falaram que não temos condições de ficar com ele. Minha mãe disse que cães fazem muita bagunça, dão trabalho, essas coisas. Mas, eu não vou deixar que soltem ele na rua".

Deve-se destacar que nas quatro histórias construídas nos grupos focais todos os animais encontrados pelos personagens eram domésticos. Em duas delas, o animal encontrado foi um cachorro; nas outras, um gato e um cavalo de carroceiro. Ou seja, animais presentes no contexto urbano e que fazem parte da vivência diária destas crianças, tal como exemplificado pelas respostas à indagação "O que Eduardo sentiu", proposta para facilitar a discussão nos grupos focais: "Alegria"; "Um sentimento de amor no coração que aqueceu o coração dele para sempre"; "Ele gostou de ter um cachorrinho para brincar"; "Gostou de ter uma amizade com ele"; "Gostou porque ele tinha uma pinta no olho e Eduardo também tinha uma pinta no olho e daí ele ficaram parecidos".

Ao se referirem a esses animais, as palavras utilizadas pelos participantes são, dentre outras, "amor", "carinho", "amizade" e "brincadeira", o que revela um universo de aspectos positivos, no qual marcadamente o afeto se destaca. Além disso, a companhia proporcionada pelo animal é ressaltada como um dos melhores ganhos na inter-relação: "Eduardo gostou que ele era alegre, era carinhoso"; "Companheiro"; "Brincalhão"; "O que ele mais gostou foi que ele era companheiro"; "Isso!".

Com pertinência aos animais abandonados, as crianças revelaram que em tal situação os animais 
ficam desamparados, o que suscita desejos e condutas de cuidado como forma de proteger ou minimizar seu sofrimento: "Eu sinto uma tristeza porque se eles tivessem uma casa pra morar eles não estariam passando fome, não estariam mexendo no lixo".

Nesta classe, a "bagunça" realizada pelos animais foi destacada como um aspecto negativo na convivência. Neste ponto houve divergências, pois alguns estudantes sugeriram a punição do animal com castigos físicos e abandono. Essa ideia, porém, foi rebatida pela maior parte das crianças para as quais este comportamento é tido como normal e, por isso, apesar de indesejado, merece uma reação pacífica: "Ele rasgou a cortina. Arranhou o sofá e fez xixi. Eduardo se espantou. Sentiu raiva"; "Botou ele pro olho da rua"; "...Eita! Eu não concordo com ela!"; " Nem eu! Porque todos os gatos fazem isso quando não têm nada para brincar... tipo uma bolinha de lã. Eles querem arranhar alguma coisa"; "Ele podia colocar o gato de castigo".

Esta classe e a Classe 3, seguinte, se relacionam pois ambas abordam a questão dos animais abandonados (cães e gatos) - e neste ponto se complementam. Mas, com a diferença de que a Classe 3 foca exclusivamente esta problemática.

- Classe 3 - Não abandonar

A terceira classe contempla $22 \%$ do corpus analisado. Trata de três aspectos relacionados à problemática do abandono de cães e gatos: os motivos pelos quais as pessoas abandonam seus animais, 0 sofrimento destes animais nas ruas e o imperativo de não abandonar juntamente com alternativas apresentadas para evitar tal prática. Pode-se, a partir das palavras mais utilizadas nos grupos focais e na leitura flutuante dos discursos, atribuir a seguinte fala aos participantes:

"O dono do cachorro o colocou na lixeira. A causa do abandono foi porque ele estava com uma doença e ele não queria ver o animal morrer. E ele ficou naquele lugar sentindo dor, frio e tristeza. O dono dele tinha era que aproveitar mais o tempo que restava com ele, ou dar pra algum amigo e não jogar ele no lixo".

Em todas as histórias construídas o personagem encontrou um animal que estava abandonado e sofrendo nas ruas. Ante este fato, todos os personagens, sensibilizados com a situação, levam o animal para casa, para ser cuidado. As razões mais citadas e discutidas pelas crianças para o abandono são: dificuldades financeiras, adoecimento do animal e comportamento indesejado: "Porque ele fez muita bagunça"; "É, tem algumas pessoas que pegam um cachorro e tratam ele bem só no começo. Se ele faz algo de errado, já coloca pra rua"; "Essa pessoa que abandonou ele não gosta muito de animais"; "Ou, às vezes, não tinha condição de cuidar direito dele".

À medida que descreviam os motivos pelos quais os animais das histórias foram abandonados, as crianças passaram a discutir alternativas de forma a evitar que o animal fique desamparado nas ruas: "Mas, se ele estava com alguma doença tinha que aproveitar mais a companhia dele como no filme do Marley. O Marley estava quase morrendo e o dono não abandonou. Até que um tempo depois ele morreu e o dono não sentiu uma dor de jogar ele dentro da lixeira pra ele sobreviver do lixo"; "Ele podia ter colocado ele em um abrigo pra ele ser adotado por uma outra família"; "Podia dar ele para alguma pessoa da família ou algum amigo".

As consequências do abandono para os animais foram enfatizadas e descritas principalmente baseadas na senciência. Assim, referem-se ao sofrimento físico (fome, dor, frio) e emocional (medo, solidão, tristeza): "Eduardo tirou o gatinho do telhado para cuidar"; "Ele ficou com dó porque ele pensou: 'ah, ele deve estar com fome, com frio. Sem amor'. E daí ele pegou ele e levou pra casa pra cuidar".

\section{Discussão}

Os depoimentos permitem afirmar que o conteúdo da representação social dos estudantes sobre os animais está fortemente ligado à figura dos animais de companhia: cães e gatos. Estas duas espécies certamente são as que os participantes mais têm contato, dentro ou fora de casa, e com as quais estabelecem relação muito próxima, baseada no afeto e no cuidado. A presença desses animais na representação era esperada, dado ser preciso que o objeto faça parte do cotidiano dos indivíduos analisados. As representações participam da construção da realidade, a qual só existe enquanto tal nas interações dos indivíduos ou grupos com os objetos sociais ${ }^{6}$.

Há grande presença desses animais no meio urbano, convivendo com as pessoas. Além dessa convivência muito próxima, atualmente há a tendência cada vez maior, na sociedade ocidental, em nutrir relação afetiva com esses animais, tornandoos membros da família. Esta realidade pode em parte ser explicada pelos benefícios que esta relação traz ao ser humano ${ }^{24}$.

Para as crianças, por exemplo, os animais de estimação podem prover companhia, segurança, conforto, diversão e afeto, bem como ensinar respon- 
sabilidade, estimular comportamento de cuidado e promover o respeito e a compaixão pelos animais e pela natureza, oferecendo à criança oportunidades para aprender sobre os animais e os fatos da vida ${ }^{25}$. Além do afeto, foi observada neste grupo social grande empatia diante das situações envolvendo, principalmente, o abandono e suas consequências de sofrimento físico e emocional ao animal.

A empatia pode ser definida como o exercício ético de se colocar no lugar do outro para avaliar uma situação, o que pode levar à preocupação com algo ou alguém além de si próprio. Assim, a empatia desempenha importante papel no desenvolvimento de um comportamento mais cuidadoso e, inclusive, na extensão do círculo da moralidade ${ }^{26}$. Com a capacidade de empatia pode-se perceber que o sofrimento do outro é semelhante ao nosso, possibilitando que a razão e a emoção ajam conjuntamente para um comportamento efetivamente ético ${ }^{26}$.

Segundo Segre ${ }^{27}$, a condição de empatia humana, que poderemos denominar também de compaixão (paixão compartilhada, que não é caridade ou beneficência) e que o filósofo Levinas caracterizou como "alteridade" (...) É necessária para que se possa "pensar bioética". Cabe ressaltar o importante papel que a empatia parece cumprir em relação a uma preocupação de natureza ética com estes animais. Ao que tudo indica, a empatia propicia a busca por condutas éticas e um olhar voltado aos animais, respeitando-os e valorizando-os por suas próprias características.

O fato de nas quatro histórias os personagens levarem os animais abandonados para casa revela atenção à fragilidade e ao sofrimento do animal, e a predisposição em ajudá-los. Mas, pela impotência na vida real, os sujeitos projetam aquilo que gostariam de fazer para livrar os animais de uma situação de sofrimento, o que pode ser resumido na ação de "cuidar", presente de forma expressiva em todos os grupos.

A ênfase no abandono de animais nas histórias possivelmente se deve à empatia e ao fato de o abandono de animais ser prática comum nas cidades, facilmente perceptível pelo grande número de animais nas ruas. Conforme estimativa da Organização Mundial da Saúde (OMS), há aproximadamente 500 milhões de cães abandonados em todo o mundo. No Brasil, são cerca de 25 milhões de cães e 10 milhões de gatos abandonados ${ }^{28}$.

Em decorrência dessa situação um questionamento se faz necessário, pois se o abandono é prática tão frequente isso demonstra que cães e gatos, apesar de apontados como os animais mais estimados pela sociedade, ainda são, muitas vezes, considerados objetos que podem ser descartados ${ }^{29}$ quando não mais atenderem às expectativas ou interesses desejados. A venda de filhotes, estimulada pelo mercado pet, propagandas e filmes voltados principalmente para o público infantil, tornam esses animais objetos de consumo, "coisas" que podem ser adquiridas sem que se tenha consciência da responsabilidade implicada ${ }^{29}$.

Outro ponto que corrobora a afirmação de um valor instrumental dado a estes animais é a antropomorfização que implica em atribuir-lhes características e concepções humanas em detrimento de suas próprias. Ao colocar bijuterias, roupas, calçados e tingir o pelo dos animais, por exemplo, os interesses dos animais e o respeito às suas próprias características ficam em segundo plano ${ }^{30}$.

Quando as crianças que participaram do estudo argumentam que o abandono não é justificável, enfatizam as consequências para os animais que, por serem sencientes, padecem de grande sofrimento. Dessa constatação decorre, portanto, a responsabilidade humana de proteger e cuidar deles. Demonstram, assim, preocupação de natureza ética quanto ao bem-estar físico e emocional dos animais, cuja manutenção depende dos seres humanos.

A preocupação com a fragilidade dos animais não humanos é uma preocupação da bioética, pois estes podem facilmente passar de um estado de vulnerabilidade para um estado de suscetibilidade e/ ou vulneração a danos ${ }^{5}$. Nesse sentido, Schramm defende que além de normativa e descritiva a bioética possui uma terceira função, também prática e socialmente relevante, que é a de proteger indivíduos contra ameaças decorrentes das práticas humanas que podem afetá-los ${ }^{31}$.

É de grande importância que na representação social destas crianças acerca dos animais estejam presentes referenciais bioéticos relacionados aos mesmos, tais como cuidado, proteção/vulnerabilidade, respeito e responsabilidade. E mais ainda, que estes sejam trabalhados na educação. No entanto, essas implicações bioéticas positivas estão restritas aos cães e gatos, pois embora outros animais apareçam nesta representação não possuem a mesma importância para as crianças, nem são da mesma forma considerados.

Conforme resultados obtidos do Eixo 1, as crianças revelaram enfoques não antropocêntricos realizados no contexto escolar. É o que se pode in- 
ferir diante das afirmativas sobre igualdade entre animais humanos e não humanos e da ênfase no sofrimento gerado aos animais silvestres quando explorados. Neste caso, diferencia-se da grande parte das abordagens que foca o número de animais mortos ou retirados da natureza e o quão isso pode prejudicar o futuro da espécie humana ${ }^{32}$.

Avançando na discussão da necessidade de proteger os animais ficou explícita a diferenciação no tratamento de diferentes animais. É o que se chama de especismo eletivo consistente em tratar de forma diferente os animais, de modo a proteger algumas espécies e discriminar outras. No especismo eletivo elegem-se alguns animais que despertam simpatia ou compaixão de tal forma que se considera importante proteger seus interesses. Porém, se permanece indiferente ao sofrimento dos animais que não se incluem no âmbito de predileção culturalmente circunscrito ${ }^{33}$. É o caso da diferença no tratamento do cão e do rato.

Segundo Naconecy ${ }^{26}$, o pensamento de senso comum é preconceituosamente discriminatório e moralmente inconsistente, com raízes culturais: $\dot{E}$ verdade que quanto mais distante de nós um animal está socialmente menos sentiremos simpatia por ele. Isso explica a tradicional preocupação humanitária por cães e gatos, e nenhuma sensibilidade pelos ratos... Mesmo que cães e ratos compartilhem as mesmas aptidões zoológicas para se converter em objeto de nossa preocupação ética. Por fim, destaca-se que a RS deste grupo social a respeito dos animais parece estar enraizada no contexto social urbano onde vivem e tendem seguir a forma como a sociedade lida com os diferentes animais conforme seus interesses.

\section{Considerações finais}

Conforme a representação social identificada nos estudantes sobre os animais, pode-se afirmar que está fundamentada no vínculo afetivo e no cuidado desses sujeitos em relação aos animais de companhia, cães e gatos. Isso significa que quando os participantes pensam nos animais, pensam especificamente nestes dois e a eles relacionam importantes referenciais bioéticos, nos quais se destacam o cuidado, a responsabilidade e a proteção.
Os elementos centrais que geram esse sistema representacional estão, portanto, ligados à figura destes dois animais domésticos e a ancoragem desta representação é feita na realidade cotidiana destes sujeitos. Outros animais, embora presentes no sistema representacional, não são centrais e não possuem a mesma importância. Apesar disso, ficou evidenciada a tendência dessas crianças em seguir o modo com que a sociedade trata os diversos animais, ou seja, especista eletiva. 0 especismo eletivo, que divide e concebe os animais de forma diferenciada, permite identificar implicações que vão na direção contrária das ideias difundidas pela bioética. Assim, em relação a certos animais, as crianças caminham para thes conceber um valor instrumental.

Este quadro pode ser explicado, em parte, pelo fato de que mesmo a escola abordando diversas e diferentes questões sobre os animais por meio da educação humanitária, no processo de construção das representações sociais os sujeitos selecionam e filtram informações de forma que apenas algumas são apreendidas. A isso, se acresce o fato de que as abordagens no contexto escolar, bem como as demais fontes de difusão de novos olhares em relação aos animais, talvez sejam ainda muito recentes para provocar mudanças reais. Desta maneira, a escola não consegue suplantar a força de determinados enraizamentos sociais relacionados aos animais, mas contribui para reforçar a assimilação de alguns valores éticos importantes em relação aos cães e gatos, que podem contribuir para a difusão do respeito a outros animais.

Estes resultados não desqualificam as iniciativas que buscam novas abordagens pedagógicas, não antropocêntricas e não especistas, como a educação humanitária. Mas indicam que esses trabalhos precisam ser intensificados e contínuos, pois diante de formas tão antigas de ver e tratar os animais as mudanças serão graduais e lentas e a intervenção cada vez mais necessária e com o devido apoio governamental. Sob tal ótica, cabe destacar a responsabilidade de os estados promoverem políticas públicas com intuito de mudar a forma com que os homens e mulheres se relacionam com os animais. Para tanto, a educação é instrumento imprescindível, em especial para as crianças, futuras tomadoras de decisão.

Trabalho elaborado durante mestrado no Programa de pós-graduação em Bioética na Cátedra Unesco de Bioética/Faculdade de Ciências da Saúde, da Universidade de Brasília (UnB). 


\section{Referências}

1. Paixão RL. Aspectos éticos nas regulamentações das pesquisas em animais. In: Schramm FR, Palácios M, Braz M, Rego S, organizadores. Bioética: riscos e proteção. Rio de Janeiro: UFRJ; 2005. p. 229-40.

2. Brasil. Lei $n^{\circ} 11.794$, de 8 de outubro de 2008. Regulamenta o inciso VII do $\S 1^{\circ}$ do art. 225 da Constituição Federal, estabelecendo procedimentos para o uso científico de animais; revoga a Lei $\mathrm{n}^{\circ}$ 6.638, de 8 de maio de 1979, e dá outras providências. Diário Oficial da União. 9 out. 2008;(196):seção I, p. 1.

3. Levai LF. Crueldade consentida: crítica à razão antropocêntrica. Rev Bras Direito Animal. 2006;1(1):171-90.

4. Kottow MH. Comentários sobre bioética, vulnerabilidade e proteção. In: Garrafa V, Pessini L, organizadores. Bioética: poder e injustiça. São Paulo: Loyola; 2003. p.71-8.

5. Schramm FR. Bioética da proteção: ferramenta válida para enfrentar problemas morais na era da globalização. Rev. bioét. (Impr.). 2008;16(1):11-23.

6. Almeida AMO. A pesquisa em representações sociais: fundamentos teórico-metodológicos. Ser Social. 2001;9:129-58.

7. Schramm FR. Información y manipulación: como proteger los seres vivos vulnerados? La propuesta de la bioética de la protección. Bioética. 2005;(1):18-27.

8. Schramm FR. Bioética, biossegurança e a questão da interface no controle das práticas da biotecnociência: uma introdução. Redbioética. 2010;1(2):99-110.

9. Batista RS, Schramm FR. A bioética da proteção e a compaixão laica: o debate moral sobre a eutanásia. Ciênc. saúde coletiva. 2009;14(4):1.241-50.

10. Assumpção ELA, Schramm FR. A ética da sabotagem da Animal Liberation Front. Repositório de Produção Científica Escola Nacional de Saúde Pública Sérgio Arouca. 2009. Disponível: www6. ensp.fiocruz.br/repositorio/resource/357037|

11. Brasil. Decreto $n^{\circ} 24.645$, de 10 de julho de 1934. Estabelece medidas de proteção aos animais. Diário Oficial da União. 13 jul. 1934.

12. Brasil. Lei $n^{\circ} 9.605$, de 12 de fevereiro de 1998. Dispõe sobre as sanções penais e administrativas derivadas de condutas e atividades lesivas ao meio ambiente, e dá outras providências. Diário Oficial da União. 13 fev. 1998.

13. Organização das Nações Unidas para a Educação, a Ciência e a Cultura. Declaração Universal dos Direitos dos Animais. Unesco; 1978 (acesso 13 fev. 2011). Disponível: http://www.apasfa.org/ leis/declaracao.shtml

14. Organização das Nações Unidas para a Educação, a Ciência e a Cultura. Declaração Universal sobre Bioética e Direitos Humanos. Unesco; 2005 (acesso 2 fev. 2011). Disponível: http://unesdoc. unesco.org/images/0014/001461/146180por.pdf

15. Moscovici S. La psychanalyse: son image et son public. Paris: PUF; 1961.

16. Jodelet D. As representações sociais. Rio de Janeiro: UERJ; 2001.

17. Vasconcellos KM. Convivendo com a alteridade: representações sociais sobre o aluno com deficiência no contexto da educação inclusiva. [dissertação]. Recife: Centro de Filosofia e Ciências Humanas da UFPE; 2008.

18. Duveen G. Crianças enquanto atores sociais: as representações sociais em desenvolvimento. In: Guareschi PA, Jovchelovicht S, organizadores. Textos em representações sociais. $5^{\text {a }}$ ed. Petrópolis:Vozes; 1999. p. 261-93.

19. Duveen G. Introdução: o poder das ideias. In: Moscovici S, organizador. Representações sociais: investigações em psicologia social. Petrópolis: Vozes; 2003. p. 7-28.

20. Abric JC. A abordagem estrutural das representações sociais. In: Moreira ASP, Oliveira DC, organizadores. Estudos interdisciplinares de representação social. Goiânia: AB Editora; 1998. p. 27-38.

21. Dal-Farra RA. Representações de animal na contemporaneidade: uma análise na mídia impressa [tese]. Porto Alegre: UFRGS; 2003.

22. Robles-Silva L. Dilemas éticos en el trabajo de campo: temas olvidados en la investigación cualitativa en salud en Iberoamérica. Ciênc. saúde coletiva. 2012;17(3): 603-12.

23. Ribeiro ASM. Macho, adulto, branco, sempre no comando? [dissertação]. Brasília: UnB; 2000. p. 156.

24. Faraco CB. Interação humano-cão: o social constituído pela relação interespécie. [tese]. Porto Alegre: PUC; 2008.

25. Serpell J. Guest editor's introduction: animals in children's lives. Society and Animals 1993;7(2):8794.

26. Naconecy CM. Ética e animais: um guia de argumentação filosófica. Porto Alegre: EDIPUCRS; 2006. p. 234.

27. Segre $M$. $O$ ensino da bioética. In: Barchifontaine $C P$, Pessini $L$, organizadores. Bioética e longevidade humana. São Paulo: Loyola; 2006. p.177-82.

28. Brandespin DF. Posse responsável e bem-estar animal. In: I Encontro de Bioética e Bem-Estar Animal do Agreste Meridional Pernambucano. 2006 (acesso 15 set. 2011). Disponível: http:// www.uag.ufrpe.br/bioetica/Palestras/Posse\%20respons\%E1vel.pdf 
29. Santana LR, Oliveira TP. Guarda responsável e dignidade dos animais. 2004 (acesso 15 set. 2011). Disponível: http://www.abolicionismoanimal.org.br/artigos/guardaresponsveledignidadedosanimais. pdf

30. Santos JR. Educação ambiental e o trabalho com valores: olhando para os animais não humanos. [dissertação]. Rio Claro; 2009.

31. Schramm FR. A moralidade da prática de pesquisa nas ciências sociais: aspectos epistemológicos e bioéticos. Ciênc. saúde colet. 2004;9(3):773-84.

32. Brugger P. Educação ou adestramento ambiental? Chapecó: Argos; 2004.

33. Felipe $S$. Dos direitos morais aos direitos constitucionais: para além do especismo elitista e eletivo. Revista Brasileira de Direito Animal. 2007;2(2):169-86.

\section{Participação das autoras}

Parte do trabalho é resultante de dissertação de mestrado de Joseth Filomena de Jesus Souza, orientada por Helena Eri Shimizu.

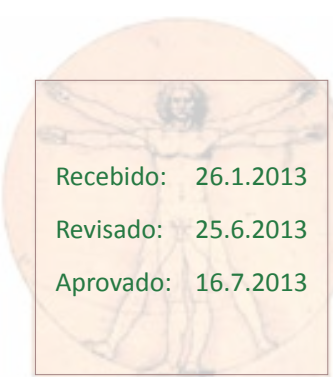

